\title{
Una nueva aproximación a las emisiones del Emirato Independiente (I38-3 | 6 H./ 755(6)-928 d. C.), y a su alcance social.
}

Manuel Castro Priego *

\section{INTRODUCCIÓN}

El desarrollo del Estado Omeya durante los siglos II-III/VIII-IX d. C. en al-Ándalus está íntimamente ligado a la creación de un nuevo sistema fiscal, que parece consolidarse de manera definitiva bajo el gobierno de al-Hakam I, en la década del 190-200 H./805(6)-8I5(6) d. C. Éste significa la aparición de un sistema relativamente centralizado, en el que vuelve a cobrar especial importancia la moneda como elemento fundamental en la política monopolística con la que el Estado intenta acaparar los excedentes campesinos. La quiebra del sistema de renta, heredero del mundo visigodo, en favor del concepto de tributo; la desaparición de aquellos grupos beneficiados por la desarticulación del Califato Omeya, junto a las nuevas dinámicas territoriales y urbanas van a ser los ejes fundamentales sobre los que se va a asentar lentamente la autoridad emiral.

\section{LA FORMACIÓN SOCIAL TRIBUTARIA ANDALUSÍ}

La fiscalidad de al-Ándalus durante el periodo emiral está directamente vinculada al tipo de organización social predominante, que imbrica a las distintas formaciones sociales presentes (CASTRO, inédito). Siempre se ha venido definiendo a la sociedad andalusí como una formación social tributaria (AMIN, 1976). En líneas generales esta estructuración social es dominante a lo largo de la historia y se caracterizaría por:

I. La base económica primordial es la producción agraria.

2. A diferencia de otros modelos sociales, no se impide el acceso de la población al medio de producción fundamental, que en este caso es la tierra. Aunque en al-Ándalus existe la propiedad privada, la unidad básica de organización social es la explotación agraria, controlada por un grupo humano campesino.

3. Existencia de una burocracia, surgida y mantenida gracias al acaparamiento de la renta campesina, pero que se mantiene en la cúspide social mediante el empleo de recursos coercitivos e ideológicos. En el caso del Islam medieval, el elemento aglutinador social es, sin duda, la religión, que convierte al Califa o al Emir en protector y director de la comunidad. Esta burocracia o administración es una estructura monopolística que controla la salida de determinados excedentes productivos campesinos, aprovechándolos en la creación de plusvalías ' que, una vez insertas en el circuito económico, provocan la aparición de formaciones sociales subsidiarias, muy ligadas al poder, como serían los grupos de comerciantes, los gremios o artesanados urbanos, y todos aque-

* Arqueólogo. Madric

I Evidentemente este concepto no se refiere a la plusvalía entendida para el Capitalismo. 
llos que alimentan y sustentan ideológicamente a la clase dirigente.

La predominancia de la formación social tributaria centralizada no significa la eliminación o desaparición de otras formaciones sociales, pero sí la jerarquización de éstas. De hecho, la aparición del Estado obliga a la paulatina eliminación o sometimiento de todos aquellos elementos intermedios ${ }^{2}$ que supongan una dificultad en el acceso o en la captación monopolística de la renta campesina. Se produce así un doble proceso:

A. El mantenimiento y crecimiento de la superestructura obliga a ésta, necesariamente, a la adquisición de todo un conjunto de bienes y a la inversión en productos que aseguren su supervivencia (bienes suntuarios, gastos militares, etc.), lo que fomenta la realidad urbana y la aparición de formaciones sociales de mercado ${ }^{3}$.

B. La imposición de un tributo asegura la continuidad del Estado y obliga a mantener una tasa de productividad que garantice la supervivencia de la comunidad fiscalizada, y el pago de lo demandado.

En este caso, y no en otro, el Estado puede optar por dos soluciones: aceptar el pago en productos agrícolas, que obligatoriamente, si quiere que resulten rentables, deben ser de larga duración; o la creación de un elemento de transacción (la moneda) que le asegure las relaciones económicas o productivas que desea y de las que espera salir beneficiado.

Así, la utilización de la moneda en al-Ándalus y su cada vez mayor importancia en las relaciones económicas y en el acaparamiento de la renta campesina, de un Estado que, por cuestiones que trataremos más abajo, está en crecimiento hasta mediados del siglo IIIH./IX d. C., tiene una importancia vital para entender la dinámica y las transformaciones sociales de un periodo importante del Medievo español.

La emisión de moneda, aunque también se cobran impuestos en especie, convierte al Estado en dinamizador del circuito económico, del proceso de intercambio, pero sin forzar la extracción o producción de un determinado bien. El campesino cultiva aquello que le asegure el pago de impuestos y su supervivencia. Es ahí donde surge la alquimia de las monedas que creadas por el Estado, permiten la aprehensión de la renta campesina y la aceleración de la economía (BARCELÓ, 1997).

Evidentemente la aparición de la burocracia y de todas las estructuras necesarias para su mantenimiento, refuerza a la ciudad como punto neurálgico en el control del territorio. Es típico de las sociedades islámicas la aparición continuada de la estructura urbana como centro del poder, no así como base de la producción económica esencial. Se tiende de una u otra forma a la centralización territorial, o local.

\section{EL PAPEL DE LA MONEDA}

La moneda va a ser un fiel reflejo de los objetivos del Estado en su reproducción y mantenimiento. Así el estudio de las emisiones monetarias, la metrología y la ley, van a poder aportarnos datos sobre el éxito del modelo creado, el alcance de éste y la capacidad del Estado para mantener su preeminencia en el circuito económico. En el presente trabajo hemos analizado, por un lado, la política monetaria del Emirato, y por otro las repercusiones en las dinámicas sociales del campesinado.

2 Con esta apreciación nos referimos a todas aquellas formaciones sociales herederas de la descomposición del reino visigodo, o surgidas durante el periodo de conquista. Sobre este aspecto, y en general, para un análisis de los procesos originados tras la caída del Imperio Romano de Occidente: WICKHAM, C (1984), "The other transition to the Ancient World to Feudalism", Past and Present, $n^{\circ} 103$, pp. 3-36.

3 No afirmamos que en al-Andalus se haya producido un progresivo avance hacia formas capitalistas, sino que en determinados lugares (por ejemplo las ciudades) existe una estructura de mercado, de intercambio de productos alejados de la base económica fundamental (la tierra), que en muchas ocasiones aparece en las estructuras tributarias centralizadas, siempre de forma marginal, y que difícilmente evolucionarán hacia el Capitalismo. 


\section{A. Las emisiones monetarias (Fig. I)}

Se desarrollan en un periodo que abarca un siglo y medio ( I 45-279 H./762-892(3) d. C.). Se distinguen dos fases; una primera que hemos denominado "fase formativa" del sistema monetario, que se caracterizaría por el lento crecimiento de las emisiones monetarias, la organización de una nueva estructura fiscal, y la circulación limitada de los especímenes emitidos. La segunda comenzaría aproximadamente en el $196 \mathrm{H./8II(2)} \mathrm{d.} \mathrm{C.,} \mathrm{y} \mathrm{coincide} \mathrm{con}$ el último decenio del gobierno de al-Hakam I y las primeras décadas del reinado de 'Abd alRaḥmān II, aumentando la producción hasta el 238 H./852(3) d. C., para estabilizarse a partir de ese momento, y descender de forma evidente a partir del 250 H./864 d. C. (CASTRO, inédito).

Con un proceso de conversión al Islam casi finalizado, las vías de expansión del sistema durante el Emirato de Muhammad I no son muy numerosas. Una posible salida sería la expansión territorial en la Marca Media y un mayor control de la Superior, junto al aumento de la presión fiscal sobre las formaciones protofeudales o feudalizantes y de la población recientemente convertida. Las relaciones del Emirato con la zona septentrional peninsular siempre fueron complicadas. Más que la imposición de la administración Omeya fuera de algunos núcleos urbanos, lo que existe es una política de alianzas y lenta imposición basada en el debilitamiento de las formaciones periféricas, fiscalizadas en la cúspide pero con una organización social y una base económica diferente a las de la administración Omeya ${ }^{4}$.
El sistema comienza a presentar serias contradicciones, especialmente a partir del 260 H./873(4) d. C., con un descenso muy acentuado de las emisiones, que coincide con las dificultades generales que parece sufrir el Emirato a partir de este momento y que va mucho más allá del problema de su capacidad militar en la Marca Media y Superior.

\section{B. Metrología y ley (Fig. 2)}

Durante el Emirato se producen dos reformas monetarias, una primera durante el gobierno de 'Abd al-Raḥmān II hacia el 21 6-21 8 H./83I-833 d. C., probablemente motivada por el reajuste del sistema que intenta adaptarse a un prolongado crecimiento de las emisiones; y una segunda hacia el 250 H./864 d. C., con el objetivo de evitar el recorte de moneda y adaptarse a un periodo de descenso de las acuñaciones.

La primera de ellas parece unida al descenso en el peso de los últimos años del gobierno de al-Hakam I, coincidiendo con el crecimiento de las emisiones. Probablemente se realizó durante el reinado de 'Abd al-Raḥmān II y tras su primera década de gobierno, en la que las emisiones no son muy numerosas, con un reajuste del peso que coincide con el periodo de máximo crecimiento de las emisiones. El peso se estabiliza, a partir de ese momento, entre 2,60 y 2,65 grs. (CANTO y MARSAL, 1986). Si anteriormente, y para otros momentos del Emirato, existía una mayor distancia entre las curvas de pesos máximos, mínimos y medios, a partir de mediados de la segunda década del siglo III H./ IX d. C. existe una notable proximidad entre las curvas, lo que demuestra la estricta política monetaria ${ }^{5}$.

\footnotetext{
4 Las dificultades para imponerse del Emirato Independiente en zonas del Norte Peninsular, no significan que no exista un destacado fenómeno de islamización.

5 Las referencias a la ceca andalusí durante el periodo emiral son escasas siendo la más significativa la del geógrafo lbn al-Faqīh (al final del siglo III H./IX d. C.) que se refiere a la existencia de la ceca establecida por 'Abd al-Raḥmān II cerca de Bāb al-Ațtārīn (la séptima puerta de Córdoba, o Puerta de Sevilla). En ningún caso se manifiesta la existencia de cecas en otros lugares. No se debe pensar en un complejo unificado, probablemente la ceca estuviese formada por varias edificaciones, que se repartirían por la Córdoba administrativa, no convirtiéndose en un recinto complejo y común hasta época de 'Abd al-Rahmān III, en el 3I6 H./928 d. C.. Lo que sí parecen demostrar las fuentes escritas es el desarrollo y reorganización que sufre la ceca andalusí tras la llegada al poder de 'Abd al-Raḥmān II (Ibn 'Id darī) que establece una nueva estructura, y un mayor control estatal de ésta que hasta entonces se encontraba "arrendada", entendiendo con esta expresión la prerrogativa concedida a un determinado grupo para que emitiese moneda de acuerdo a unos cánones establecidos. Probablemente, se produce una delegación consentida del Estado, favoreciendo la producción a través de varios funcionarios que obtendrían una cantidad variable y pactada. La reforma fiscal llevada a cabo por este emir significa un mayor control de la ceca así como un control más exhaustivo de las emisiones, en una clara intención de aumentar los volúmenes de producción. Es posible que muchos de los signos y letras que aparecen en las monedas emirales sean marcas de control de la ceca que recogen, en algunos casos, el nombre de funcionarios de las cecas, o menciones coránicas.
} 
Esta primera reforma parece venir acompañada de un ligero descenso en la ley ${ }^{6}$, que se sitúa entre el 80-90\%, para descender, aproximándose más al primer valor, a medida que avance el reinado del cuarto emir. Es evidente, por tanto que existe una estrecha relación entre el descenso del peso del dirham, la reducción de la ley y el crecimiento de las emisiones monetarias.

La política seguida por al-Hakam I y su hijo parece pretender fiscalizar el máximo de población posible, viéndose probablemente favorecidos en su intento por las conversiones masivas, que deberían estar prácticamente finalizadas en el primer tercio del siglo III H./IX d. C. en la zona sur peninsular, lo que explicaría el crecimiento continuado de las emisiones, y del Estado Omeya. El alcance territorial de la política seguida debió ser notable.

La otra reforma se produce hacia el $250 \mathrm{H}$. 1864 d. C., y busca un mayor control del sistema monetario, que en la década anterior mostraba ligeros signos de estancamiento. Por una parte se pretende controlar en mayor medida la ley de la moneda, que se había situado entre el 70-80\%, entre el 230-240 H./844(5)$854(5)$ d. C., y que se había elevado al $80 \%$ entre el 240-250 H./854(5)-864 d. C. Por otra, se intenta acabar con el fenómeno de recorte de las monedas, que debía significar una pérdida destacada de especímenes.

Aparecen, a partir de este momento, monedas de módulos más grandes, con una epigrafía legible, y unas orlas claramente identificables, que eran más difíciles de modificar que las anteriores $^{7}$. Se pretendía acabar, por tanto, con el fraude que había significado el recorte de monedas. Los intentos por estabilizar el sistema parecen entrar en crisis a partir del 257 H./870( I) d. C., con un descenso casi continuado de las emisiones a partir de entonces, aunque la ley parece seguir aproximándose al 80-90\%. La quiebra del sistema estaba próxima. Tras la muerte de Muhammad I, las emisiones se convirtieron en residuales. Dada la imposibilidad del Estado de continuar su política fiscal, y la escasez de ingresos, con la ausencia o usurpación del pago de la yibaya de los insurrectos, no se logró la estabilización del sistema.

Baste para comprobar la situación del final del Emirato la cita clásica de lbn Hayyān sobre el emir 'Abd Allāh, "cuyo gobierno fue constantemente conmovido por revueltas y rebeliones internas, y cuya vida fue amargada por diversas causas, entre otras los pocos recursos impositivos de la Corte y los exiguos ingresos, que determinaban las remuneraciones escasas de los funcionarios y del ejército, y la distribución limitada del numerario y los víveres para el abastecimiento de la ciudad y Azzacat" (GURAIEB, 1950-1959).

\section{DINÁMICA SOCIAL}

El crecimiento de las emisiones monetarias, parece en todos los casos estar íntimamente unido al control de los excedentes campesinos y a la reorganización del territorio, promovida por el Estado a partir de finales del siglo II H.NIII d. C., especialmente en la zona sur peninsular, y tal vez muy vinculado al proceso de islamización general que se vive en este periodo, como ya se ha mencionado. Las limitaciones del modelo creado parecen darse a partir del 250 H./864 d. C., en que ya no encontramos un sistema monetario "ofensivo", sino más bien una política orientada a salvaguardar los especímenes emitidos, y a aumentar lentamente la recaudación, en un proceso de aumento de la tensión social que acaba culminando con la primera fitna.

La respuesta de la población al modelo creado se produce de varias formas. Una de ellas es sin duda la aceptación de la moneda como elemento estructurador de las relaciones económicas inmediatas. El recorte de monedas,

6 Agradezco la información entregada por A. Canto, dentro del proyecto que dirige sobre el estudio de la Colección de moneda hispano-árabe del Museo de la Casa de la Moneda. En estudios posteriores complementará los datos a los que yo me refiero de manera esquemática sobre la ley de la moneda andalusí.

7 Nos referimos a las monedas clasificadas con el estilo C, D, E, F, G de Miles, y la $3^{\mathrm{a}}$ y $4^{\mathrm{a}}$ Acuñación de Vives. 
que es especialmente importante a partir del gobierno de al-Hakam I, muestra la generalización del empleo de la moneda en amplios sectores, probablemente de zonas urbanas, que se abastecen de subdivisores, no emitidos por el Estado en un porcentaje suficiente, o en un metal apreciado.

Se observa una evolución, que comenzaría con pequeños recortes de las orlas, que en principio, podían aprovechar el sobrepeso de algunos ejemplares, para convertirse en un recorte total de ellas, y la aparición de moneda fragmentada, en un porcentaje elevado, a partir del reinado de 'Abd al-Raḥmān II (Fig. 3). Los objetivos de este proceso son obvios, abastecerse de subdivisores, que el Estado no emitía, para su uso en las transacciones cotidianas (MARINHO, 1984). Es posible, y hay suficientes elementos para confirmarlo que el Estado acuñó fulüs a mediados del siglo III H./IX d. C., pero desconocemos en qué cantidad. Lo que parece lógico es que el grueso de las acuñaciones debieron seguir teniendo como principal metal la plata. Debió existir también un rechazo de ellos por parte de la población que continuó el proceso de recorte, colocando fuera del sistema monetario a los especímenes de cobre. Era algo irremediable, independientemente del rechazo de la sociedad islámica a las monedas de este metal; el Estado continuó exigiendo sus impuestos en plata $u$ oro.

El recorte de monedas podría haber sido un proceso permitido por el poder Omeya, durante el crecimiento de las emisiones monetarias; si no fue así tendremos que suponer su incapacidad para evitarlo. Si existe un recorte indirecto de las piezas (recorte de orlas, etc.) debemos deducir que durante un tiempo se debieron exigir los impuestos a la talla; si no, se hubiese practicado la fragmentación directa. Esa situación debió cambiar rápidamente y exigirse los impuestos al peso, bi-l-waẓina, lo cual resolvía el problema. Pero a partir del $250 \mathrm{H.} /$ 864 d. C. parece existir un deseo de acabar con el recorte de monedas, que estaría unido a una doble realidad: por una parte, el Estado sigue cobrando los impuestos al peso, admitiendo aquellos ejemplares emitidos con anterioridad al 250 H./864 d. C.; por otra, intenta preservar los nuevos especímenes, mediante su circulación a la talla.

Sin ninguna duda, la nueva fiscalidad era un elemento de conflicto frente a todos aquellos grupos sociales que se veían perjudicados por la política estatal, motivando en un periodo amplio diferentes tensiones, resueltas de forma mucho más limitada en la Marca Media y Superior.

En líneas generales, todos aquellos que tuvieron una actitud pactista con los conquistadores mantuvieron muchas de sus prerrogativas. En las fuentes islámicas se nos menciona en varias ocasiones a Teodomiro, Ardabasto, Sara la Goda, pero también a grupos que se diluyen mucho más lentamente y que mantendrán un claro control de amplias zonas peninsulares, en algunas ocasiones con una actitud claramente opuesta al poder de Córdoba, como serían claro ejemplo los Banū Qasī. A estos grupos de origen anterior, aristocrático, que basan fundamentalmente su poder en la servidumbre, en el establecimiento de lazos clientelares, se opuso la nueva formación social islámica (ACIÉN, 1994).

Los grupos nobiliarios se ven claramente perjudicados por las características antropológicas de la familia de origen islámico que tiende a absorber elementos femeninos, sin debilitarse o provocar la desaparición del elemento masculino, troncal y vertebrador en la sociedad islámica. Así se establecen sistemas de integración que aseguran la desaparición de estos grupos, bien mediante la paulatina absorción, o a través del debilitamiento ideológico (GUICHARD, 1976).

Tenemos varias noticias de colaboración de cuadros eclesiásticos con el poder Omeya, tanto en época emiral como califal. Herederos de uno de los grupos de poder más importantes de época visigoda, mantuvieron una actitud de

8 Sin ninguna duda, de forma clara en zonas urbanas, aunque fuera de allí, la situación debió ser notablemente diferente. 
colaboración con el emir. Prueba de ello sería la llegada a Córdoba del obispo Hostégesis para entregar los impuestos al emir, junto con otras referencias anteriores.

El papel importante jugado durante los siglos VI y VII d. C., no lo van a realizar en época islámica, fundamentalmente por dos razones: una la religiosa, y otra su incapacidad para intervenir en la organización administrativa. La evolución del Emirato producirá un paulatino ataque a la base económica y social de la iglesia, al producirse el proceso de conversión.

Lógicamente se van a producir distintos procesos de asimilación a la, cada vez más consolidada, formación social islámica. En líneas generales, desde el punto de vista fiscal, la clara dicotomía religiosa y la mayor carga fiscal que soportan los no musulmanes tiene que incitar, de una u otra forma, a la conversión al Islam, sobre todo si la presión fiscal sobre estos grupos tiende a aumentar. También es cierto que la base económica de la aristocracia de base feudal probablemente no empieza a ser minada hasta bien entrado el siglo III H./IX d. C.

Mención aparte merecen los ŷund-s que basaban su poder en el control administrativo de amplios espacios en el sur de al-Ándalus, junto a grupos árabes, que habían sufrido un claro proceso de aristocratización y de unión con grupos de poder locales de origen anterior.

\section{EL ORIGEN DE LAS ACUÑACIONES}

\section{(Fig. 4)}

La llegada al poder de 'Abd al-Raḥmān I en el 138 H./755(6) d. C. no significó una ruptura inmediata de determinadas dinámicas, pero sí la paulatina consolidación de una formación social que tiende a organizarse de manera centralizada y tributaria, enfrentándose muchas veces a estructuras de origen anterior, o de reciente aparición, resultado del proceso de conquista, de la desarticulación del estado visigodo o del desmantelamiento de la primera organización creada por el Califato de Damasco tras el $92 \mathrm{H} . / 7$ I I d. C.

La desaparición de la administración provincial tras el golpe de estado abbasí provocó la suspensión de la acuñación de moneda íntimamente ligada al mantenimiento de dicha estructura administrativa y del ejército, y poco imbricada posiblemente en la dinámica social. Tras las últimas emisiones de dirhemes ${ }^{9}$ en el I 35 H./752 d. C., no se vuelven a acuñar hasta el 145 H./763 d. C.

'Abd al-Raḥmān I, tras su llegada, tarda siete años en emitir las primeras monedas de plata, y sólo a partir del I50 H./767 d. C. éstas no son testimoniales. La pregunta clave tal vez sería si en estos momentos la moneda es el elemento de tributación dominante; o si se trata de la herramienta fundamental empleada por el Estado, en las relaciones que mantiene dentro de un panorama heterogéneo y en el que probablemente existan distintas formaciones sociales, desde algunas urbanas, hasta otras con claras estructuras protofeudalizantes. No parece ser así, lo que nos obliga a cuestionarnos qué tipo de instrumentos emplea el Emirato, que no parece consolidado hasta bien avanzado el reinado.

El análisis del registro numismático ${ }^{10}$ realizado ha ratificado la propuesta sostenida hace algunos años, que ponía en tela de juicio los enfrentamientos y sublevaciones durante el gobierno del primer emir, como simples con-

\footnotetext{
9 Es probable, que existan monedas de cronología posterior, aunque sin ninguna duda, en un volumen muy reducido.

IO El estudio presentado ha tenido como base fundamental el Fondo General de dirhemes del Emirato Independiente del Museo Arqueológico Nacional, integrada por algo más de 1400 piezas, a las que se han sumado, para el caso del reinado de 'Abd al-Raḥmān I, los datos de varios tesoros y colecciones, según los siguientes criterios:

Todos aquellos que tuviesen estudios metrológicos que incluyesen análisis sobre las modificaciones que hemos considerado en nuestra propuesta: perforaciones, recortes, fragmentos de moneda, etc. Así los tesoros son lznájar (CANTO Y MARSAL, I988), Carmona (PÉREZ-SINDREU, 1988), Algarve (MILES, 1960), Arraiolos (RODRIGUES MARINHO, I983), Cazalla (IBRAHIM Y CANTO, I99I), Pedreguer (NAVARRO OLTRA, 1987), La Lantejuela (RUIZ ASENSIO, 1967), y Córdoba (CANTO, 1987).

Merecen un trato diferente, incluyéndose únicamente el número de monedas, Estella (MATEU Y LLOPIS, I950) y (NAVASCUÉS, 1957), Sagrada Familia (SANTOS GENER, 1956).
} 
flictos tribales (MANZANO, 1993). La importancia de los ŷnd-s en el periodo anterior ha sido destacada no sólo por investigaciones recientes, sino por trabajos más clásicos (CHALMETA, 1975). Sin duda, ejercían una función de control importante de la recaudación de la tributación cristiana en los sectores del sur de alÁndalus (obtienen 1/3 de la recaudación total de cada demarcación), donde estuvieron asentados, y se veían beneficiados por una fiscalidad en la que sólo debían pagar un canon fijo a la administración. La relación de estos grupos con las distintas revueltas que afectan al sur de la Península durante la primera fase del gobierno de 'Abd al-Raḥmān I es evidente. Todas ellas se observan claramente en el registro numismático (Fig. 4) y en los niveles de emisión de moneda, poniendo de manifiesto cómo se articula la primera organización del Estado (CASTRO, en prensa). Especialmente virulenta parece ser la sublevación de los ŷnd-s de Hims y Egipto, hacia el I54 H. /770( I ) ó I 56 H./772(3) d. C., que coincide con la de Šaqyà al-Miknasī en la Marca Media (MANZANO, 199I), justo en el momento de inflexión en el crecimiento de las emisiones monetarias.

Es muy significativo que las emisiones se generalicen justamente en el momento en que se resuelven de manera definitiva las primeras revueltas de varios $\hat{y} u n d-s$ que se habían producido en el Valle del Guadalquivir y que se habían dado, en distintas etapas, entre el 139 H./756 d. C. y el I 49 H./766 d. C., para ralentizarse a partir de este momento. De hecho, desde el 150 H./767d. C., hasta el I 55 H./77 I d. C. las emisiones aparentan ser muy importantes y en continuo crecimiento, hasta el I55I 56 H./77/ I-772 d. C., en que se produce un fuerte descenso coincidiendo con la última gran sublevación en el Valle del Guadalquivir, llegando a ocuparse Sevilla y resolviéndose la situación en la batalla del río Bembézar. La cronología que aparece en las fuentes para este acontecimiento es muy similar tanto en el Ajbār Maŷmū'a, como en cronistas más tardíos (Ibn 'Iḍārī e lbn al-Ațiir). Estamos ante grupos que controlan y explotan a su favor un territorio, y cuya situación va a ser modificada lentamente a partir de 'Abd al-Raḥmān I para ser claramente diferente en época del cuarto emir (SALVATIERRA, 1998). Es ahora, mediados del siglo III H.IIX d. C., cuando parecen desaparecer de manera definitiva el control sobre la recaudación que ejercen los ŷnd-s y sobre todo, se produce una amplia política de reorganización territorial, con la construcción de nuevos centros, algunos ex-novo, y otros como resultado de la revitalización de núcleos con escasa importancia anterior, que sirven para el establecimiento de la administración, construyéndose asentamientos neurálgicos, de clara naturaleza urbana, y que demuestran una política centralizadora"' (Jaén, Murcia).

\section{EL PROBLEMA CAMPESINO}

El estudio de la fiscalidad de época emiral ha puesto de manifiesto el objetivo último del proceso fiscal: el acaparamiento de la renta campesina. Sin embargo, bajo esta aparente obviedad, no se ha producido una sistematización suficiente de las pautas seguidas por el nuevo Estado, ni las repercusiones que se provocan en la organización interna del campesinado.

Las vías de salida que sigue el excedente campesino, y su repercusión en los procesos de trabajo se han convertido en el elemento crucial para comprender las relaciones entre la base económica fundamental (la tierra) y el Estado. Recientemente Haldon (HALDON, 1993), profundizando en este concepto, ha optado por con-

\footnotetext{
I I Existen además otros grupos no asimilados, o que se resisten a la nueva realidad. Éstos han sido definidos con especial brillantez por Acién Almansa (1994 y 1998). Dentro de ellos, existe un amplio espectro de grupos que cumplen casi todos ellos, algunas características que se oponen a las que son los dos rasgos fundamentales de la formación social islámica, lo urbano y lo privado. Son grupos que basan fundamentalmente sus vínculos a través de la servidumbre, y que por lo tanto, no cumplen las normas básicas de la sociedad islámica.

La clara prueba de la supervivencia de relaciones de servidumbre se observa en la figura de 'Abd Allāh b. Yahya, 'āmil de la frontera en época de 'Abd al-Raḥmān II, poseedor de una estructura clientelar militar (gilmān), con la que controla la región de Tortosa, siendo sus miembros pagados por el erario público, y no distinguiéndose en este caso la diferencia entre lo público y lo privado.

Este ejemplo es un claro dato de lo matizadas que se encontraban las relaciones sociales en ámbitos periféricos, en los que el poder Omeya se mantenía con dificultad y sólo apoyándose sobre formaciones sociales protofeudales.
} 
siderar a lo feudal y a lo tributario como una misma cosa, en la que lo definitorio son los procesos de distribución o acaparamiento del excedente por parte de la superestructura, quedando en segundo término de qué manera se realizaban éstos ${ }^{12}$. La realidad, sin embargo, es que toda acción de captación tiene repercusiones en el campesinado, que si bien no tienen por qué significar un cambio en las relaciones de trabajo, sí en las dinámicas sociales del grupo.

Hasta ahora se ha venido defendiendo, de forma más o menos explícita, la aparente libertad del campesinado andalusí en la organización de sus procesos de trabajo, y la maximización de los excedentes. Si bien es cierto que, a diferencia de la estructura feudal, el grupo campesino tiene una gran libertad en la elección de su gestión del espacio inmediato, no hay que olvidar que las dinámicas que sigue son resultado directo del tipo de estructura social que tiene, y del grado de coerción o de la acción depredatoria que se produzca sobre él.

No lo olvidemos, no existe una relación ingenua entre el campesinado y la burocracia Omeya, en la medida en la que la segunda sólo puede existir al obtener parte de los excedentes de la primera. El Estado no se convierte en un mero espectador, sino que es consciente e interviene en las dinámicas seguidas por el campesinado, fomentándolas en algunos casos e interviniendo de forma directa, mediante la creación de instrumentos que le permitan alcanzar sus objetivos (la moneda), y revertir sobre él todo el circuito productivo. Así, se prefiere el control sobre comunidades, como forma de alcanzar una mejor gestión del tributo. La propia comunidad queda implicada en la recaudación y en la vigilancia de su entrega, evitando las deserciones que perjudican al resto de la comunidad (MANZANO, 1998).

La imposición fiscal, por otro lado, puede acarrear una aceleración de las relaciones ver- ticales en el grupo campesino, en el que determinados prohombres pueden ejercer las labores de control sobre los excedentes en beneficio de la comunidad, convirtiéndose en el nexo de unión entre el campesinado y la administración Omeya. En el caso de producirse una cierta jerarquización en el grupo, éste queda directamente ligado a la superestructura mediante la vinculación establecida entre los líderes y el Estado, que les confiere nuevas funciones a ejercer en su jefatura (WOLF, 1987). Este proceso casi nunca se presenta de forma tan contundente; existen múltiples elementos que colaboran en él: desde ideológicos -la propia religión, la solidaridad y respeto por las normas del grupo, la jerarquización de éste, la figura del líder- hasta otros que se oponen: la rigidez de las normas consuetudinarias ${ }^{13}$, las propias limitaciones que impone el espacio agrario.

Esto implica necesariamente un análisis de las estrategias diferentes que adopta el campesinado, no en su trabajo, pero sí en las pautas de organización de su excedente, dependiendo de la forma en que se ha propuesto la superestructura obtenerlo. El elemento de unión se produce con la salida del producto, y sin él no hay Estado porque, si bien el campesinado puede existir sin él, este último no puede hacerlo sin el primero, aunque a veces nos deslumbre y lo convirtamos en el único motor histórico.

La diferencia entre Feudalismo y modelo tributario centralizado ratifica la propuesta. En el caso del segundo el excedente campesino se convierte en moneda; en el primero este proceso no es necesario, porque existen otros medios de consecución de la renta campesina, aunque en ambos casos, indudablemente, el objetivo es el mismo. Es, por tanto, la capacidad de imponer sus condiciones y fines lo que parece caracterizar la dialéctica entre superestructura dominante y campesinado, en una relación que, sin duda, sólo se hace mediante la coerción en cualquiera de sus formas o grados.

12 Creemos que sigue existiendo una diferencia, en resumen dos modelos. Debemos profundizar, no sólo en el conocimiento de las pautas seguidas por la superestructura en la aprehensión de la renta campesina, sino, y esto es fundamental, en la ruptura de la cohesión del grupo campesino y en la introducción de nuevas dinámicas, que parecen ser mucho más intensas en la imposición de un modelo feudal.

I3 La aceptación por la comunidad del "dirigismo" que practica el líder en la acumulación y salida del excedente, se convierte en uno de los elementos de máxima tensión social. 


\section{BIBLIOGRAFÍA}

ACIÉN ALMANSA, M. (1994), Entre el Feudalismo y el Islam. 'Umar ibn Hafșūn en los historiadores, en las fuentes, y en la historia, Jaén.

$æ$ ( 1998), "La desarticulación de la sociedad visigoda", Hispania, al-Ándalus, Castilla. Jornadas Históricas del Alto Guadalquivir, Jaén, pp. 45-68.

AJBĀR MAŶMU 'A (1867), (colección de tradiciones), Lafuente Alcántara, E. (ed. y traducción), Madrid.

AMIN, S. (1976), Sobre el desarrollo desigual de las formaciones sociales, Barcelona.

BARCELÓ, M. (1979), "On coins in al-Ándalus during the Umayyad Amirate (138-300)" Quademi Ticinesi. Numismatica e Antichità Classiche, 8, pp. 313-323.

- (1985), "Un estudio sobre la estructura fiscal y procedimientos contables del Emirato Omeya de Córdoba (|38-300/755-9/2) y del Califato (300-366/9|2-976)", Acta Medievalia, 5-6, Barcelona, pp. 45-72.

- (1997), "'"Ruedas que giran en el fuego del infierno" o ¿para qué servía la moneda de los taifas?", El sol que salió por occidente. Estudios sobre el Estado Omeya en al-Ándalus, Jaén.

BARCELÓ, M. y RETAMERO, F. (1996), "From crops to coins, which way back?", Gaceta Numismática, 122, Barcelona, pp. 53-60.

CANTO, A. (1988), "Tesoro de moneda emiral del siglo II de la Hégira conservado en el M.A.N." Jarique de Estudios Numismáticos Hispano-Árabes, I, Zaragoza, pp. $147-$ 162

- (1993),"Sobre un pequeño hallazgo de moneda emiral en Martos (Jaén)", Antiquitas, 4, Córdoba, pp. 63-66.

- (1994) "De contenidos metálicos en la moneda hispano-árabe de época omeya", Anaquel de Estudios Árabes, V, Madrid, pp. 275-297.

CANTO, A. y MARSAL, E. (1986), "On the metrology of the silver coinage of the Spanish Amirate", Problems of Medieval Coinage in The Iberian Area, 2, Avilés, pp. 167-180.

— (1988) "Hallazgo de moneda emiral de Iznájar (Granada)", Al-Qantara, 9, Madrid, pp. 427-470.

CASTILLO ARMENTEROS, J. C. (1998), La campiña de Jaén en época Emiral (s. VIII-X), Jaén.

CASTRO, M. (en prensa) "Las primeras emisiones monetarias del Emirato Independiente: las acuñaciones de 'Abd al-Rahmān I. Circulación e Imposición fiscal", X Congreso Nacional de Numismática, Albacete, 1998.

- (inédito), La circulación monetaria en época Omeya Emiral: la colección del M.A.N., Memoria de Licenciatura, Julio de 1999, Universidad Autónoma de Madrid.

CHALMETA, P. (1975), "Concesiones territoriales en alÁndalus (hasta la llegada de los almorávides)", Cuadernos de Historia, VI, pp. 37-48.
FAGNAN, E. (1898), Annales du Maghreb et de I'Espagne, Argel.

-(190 I-1904), Histoire de I'Afrique et de l'Espagne intitulée al Bayano'l-Mogrib, 2 vols., Argel.

GARCÍA GÓMEZ, E. (1957), "Unas «Ordenanzas del Zoco» del siglo IX: Traducción del más antiguo antecedente de los tratados andaluces de «hisba» por un autor andaluz", Al-Ándalus, XXII, Madrid, pp. 253-316.

GILMAN, A. (1997), "Cómo valorar los sistemas de propiedad a partir de datos arqueológicos", Trabajos de Prehistoria, 52, n², pp. 81-92.

GUICHARD, P. (1976), Al-Ándalus. Estructura antropológica de una sociedad islámica en Occidente, Barcelona.

GURAIEB, J. E. (1950-1959), "Al-Muqtabis de Ibn Hayyān", Cuadernos de Historia de España, XIII-XX, Buenos Aires.

HALDON, J. (1993), The State and the tributary mode of production, Londres.

-(1998a), "El modo de producción tributario: concepto, alcance y explicación", Hispania, LVIII/3, núm. 200, pp. 795-822.

-(1998b), "La estructura de las relaciones de producción tributarias: estado y sociedad en Bizancio y el Islam primitivo", Hispania, LVIII/3, núm. 200, pp. 84I-879.

IBRAHIM, T. y CANTO, A. (|99|), "Hallazgo emiral en Puebla de Cazalla (Sevilla)", Numisma, 229, Madrid, pp. 69-86.

MANZANO MORENO, E. (|99|), La Frontera de alÁndalus en época de los Omeyas, Madrid.

- (1993) "El asentamiento y la organización de los ŷund-s sirios en al-Ándalus", Al-Qantara, XIV, fasc. 2, Madrid, pp. 327-359.

-(1998), "Relaciones sociales en sociedades precapitalistas: una crítica al concepto de 'modo de producción tributario"', Hispania, LVIII/3, núm. 200, pp. 88I-9I3.

MATEU Y LLOPIS, F. (1950), "El hallazgo de dirhemes del Emirato en San Andrés de Ordoiz (Estella, Navarra)", Príncipe de Viana, año Xl, núms. XXXVIII y XXXIX, pp. $85-101$

MILES G. C. (1950), The Coinage of the Umayyads of Spain, 2 vols., New York

-(1960), "A hoard of arab-dirhams from Algarve, Portugal", American Numismatic Society Museum Notes, 9, pp. 217-230.

NAVARRO OLTRA, V. (1990), "Hallazgo de dirhemes en Játiva", Gaceta Numismática, 97-98, Barcelona, pp. 125127.

- (1987) "Un tesorillo de dirhemes emirales en Pedreguer (Alicante)", II Congreso de Arqueología Medieval Española, vol. 3, Madrid, pp. 53-6I. 
NAVASCUÉS, J. (1957), "Revisión del tesorillo de dirhams de San Andrés de Ordoiz, Estella, (Navarra)", Príncipe de Viana, 66, pp. 10-37.

- (1954), "Revisión del tesorillo de dirhams de San Andrés de Ordoiz", Numario Hispánico, tomo III, n 5, Madrid, pp. 237-249;

RODRIGUES MARINHO, J. ( 1983): "Uma prática singular en moedas do Emirato do Andalus", O Arqueólogo Português, serie IV, I, pp. 347-374.

RUIZ ASENCIO, J. M. (1967), "Tesorillo de «dirhemes» del Emirato hallado en La Lantejuela (Sevilla)", Numisma, $n^{\circ}$ 84-89, Madrid, pp. 27-50.

SALVATIERRA CUENCA, V. (1998), "La génesis de la ciudad islámica en las campiñas del Alto Guadalquivir", Hispania, al-Ándalus, Castilla. Jomadas Históricas del Alto Guadalquivir, Jaén, pp. ||3-134.

\section{RESUMEN}

Se presenta un estudio de las emisiones del Emirato Independiente, y de la repercusión de la nueva política fiscal en el campesinado. Las relaciones centro-periferia, junto a la reciente discusión sobre el modo de producción tributario, y su alcance, complementan el trabajo.

\section{PALABRAS CLAVE:}

Emirato Independiente, campesinado, emisiones monetarias, política fiscal.
SANTOS JENER, S. (1956), "Monedas carolingias en un tesorillo de dirhemes del Emirato cordobés", Numario Hispánico, tomo $\mathrm{V}, \mathrm{n}^{\circ}$ 9, Madrid, pp. 79-87.

VICENT, J. M. (1998), "La prehistoria del modo tributario de producción", Hispania, LVIII/3, núm. 200, pp. 823839.

VIVES Y ESCUDERO, A. (I893), Monedas de las dinastías arábigo-españolas, Madrid.

WICKHAM, C. (1984), "The other transition to the Ancient World to Feudalism", Past and Present, n 103 , pp. 3-36.

WOLF, E. (1987), Europa y la gente sin historia, México.

\section{ABSTRACT}

This work is a study about of the Umayyad Amirate coinage, and the repercussion in the peasantry. The connection between center-periphery, and a new approach about the discussion of the concept "tributary mode of production", are the other questions studied.

\section{KEY WORDS:}

Independent Amirate, peasantry, coinage, fiscal policy. 


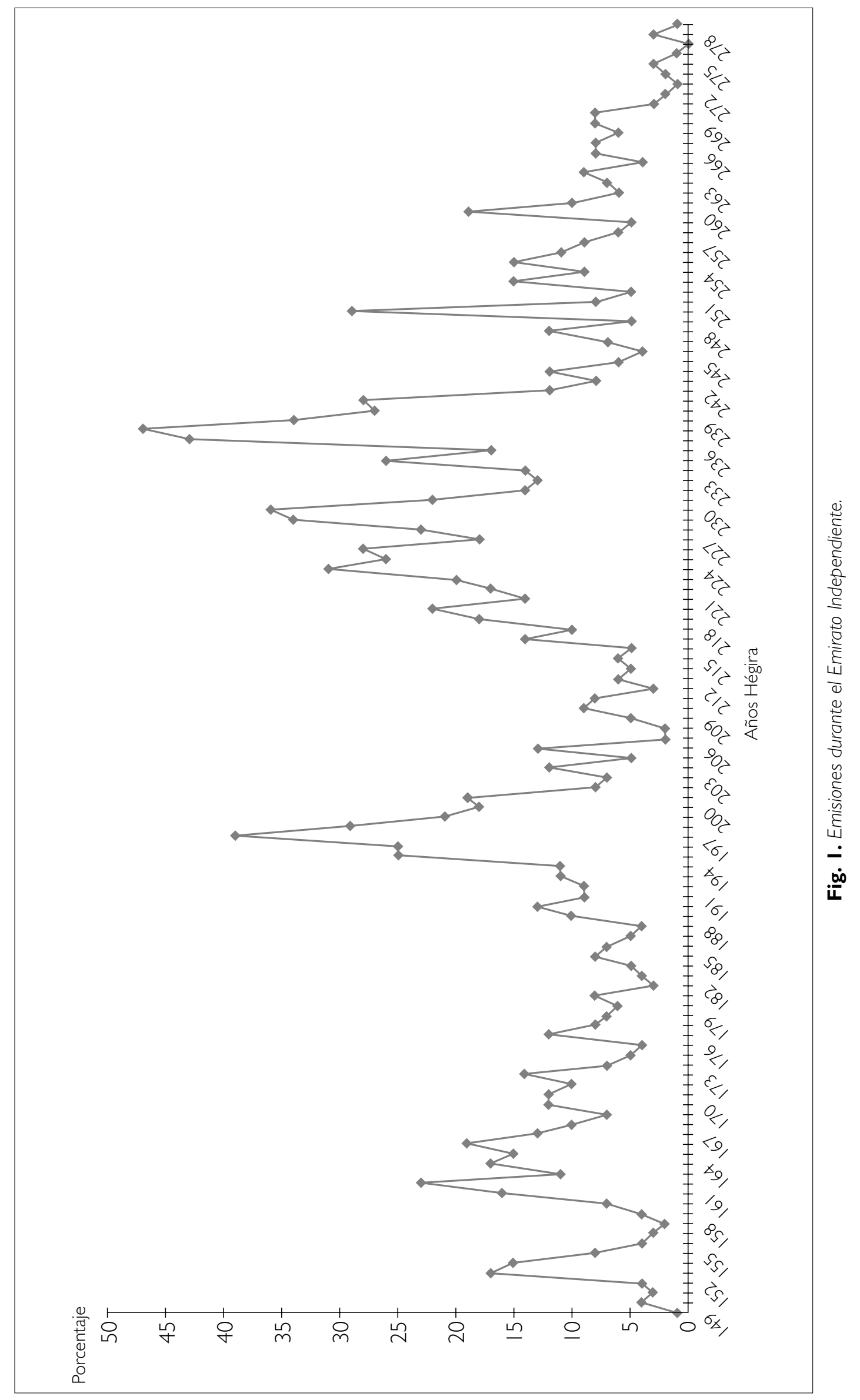




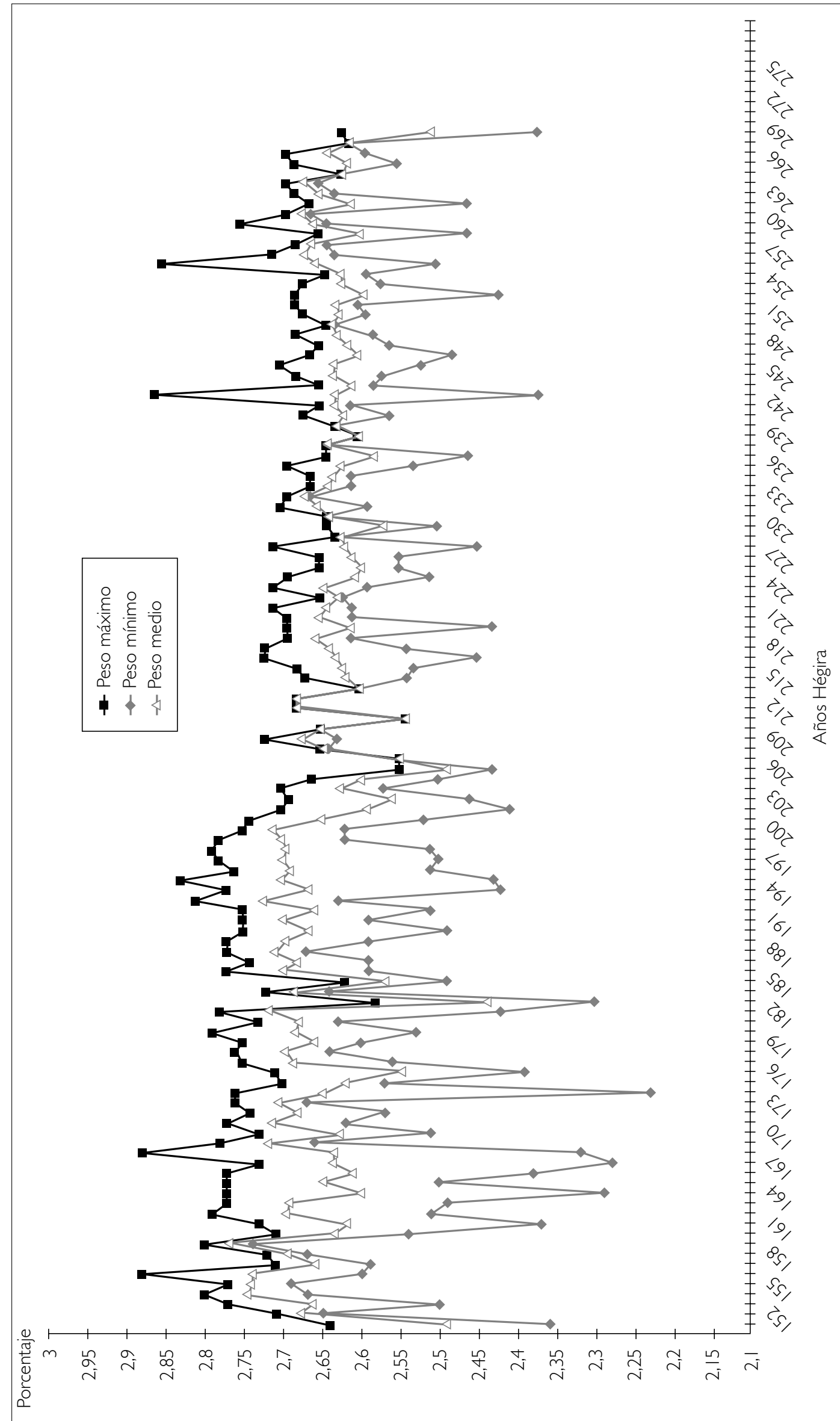

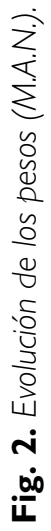




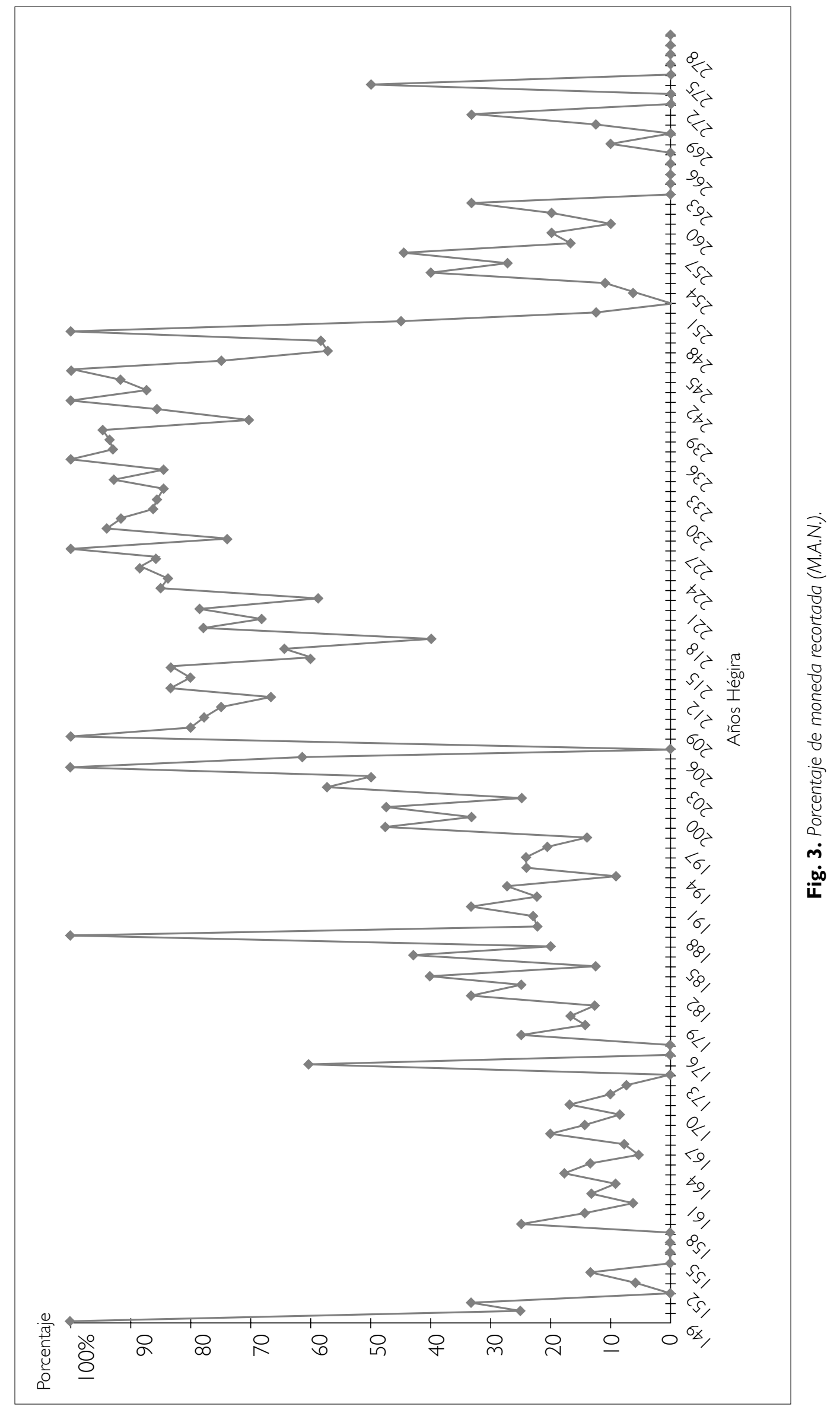




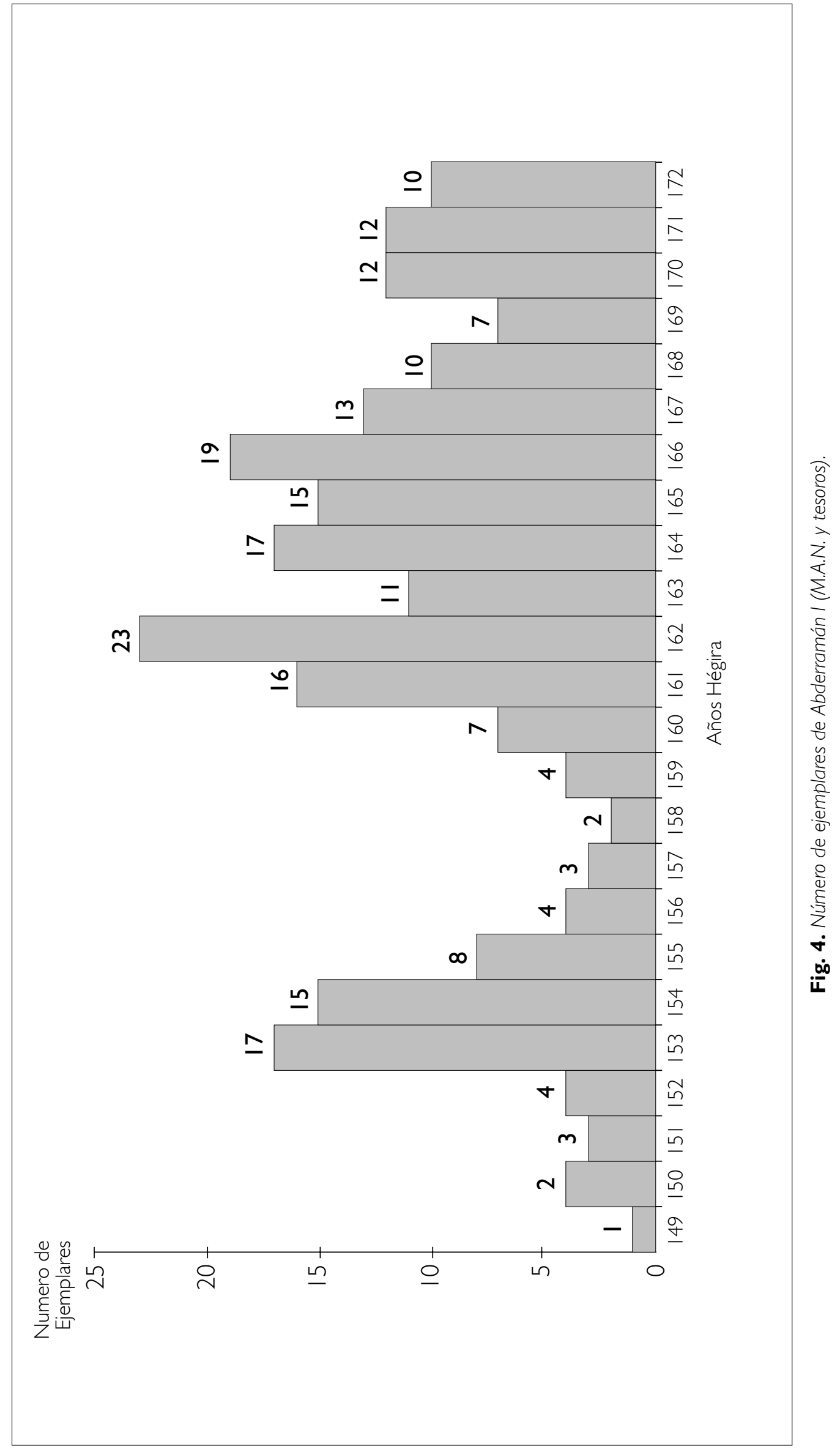

